\title{
Falar o Sofrimento de Vidas Presas: uma Política da Narratividade
}

Talking the Suffering of Lives Arrested: a Policy of Narrativity

Hablando el Sufrimiento de Las Personas Detenidas: una Política de La Narratividad

\begin{abstract}
Alyne Alvarez Silva
Graduação em Psicologia (2006) e Mestre em Psicologia Social pela Universidade Federal do Pará (2009). É professora da Universidade da Amazônia (UNAMA) e doutoranda no Programa de Psicologia Social da Pontifícia Universidade Católica de São Paulo/PUC-SP. Membro do Movimento Paraense da Luta Antimanicomial/MLA-PA, que integra a Rede Nacional Internúcleos da Luta Antimanicomial/RENILA.

Email: alvarezalyne@gmail.com

\section{Maria Cristina Gonçalves Vicentin}

Graduação em Psicologia pela Pontifícia Universidade Católica de São Paulo (1983), Mestrado em Psicologia Social (1991) e Doutorado em Psicologia Clínica (2002) pela Pontifícia Universidade Católica de São Paulo. É Professora Doutora do Programa de Pós Graduação em Psicologia Social da Pontifícia Universidade Católica de São Paulo, onde coordena o Núcleo de Lógicas Institucionais e Coletivas.

Email: mvicentin@pucsp.br
\end{abstract}

\section{Resumo}

O artigo aborda o sofrimento de vidas reclusas em um manicômio e um simulacro de manicômio, respectivamente: o Hospital de Custódia e Tratamento Psiquiátrico do Pará e a Unidade Experimental de Saúde de São Paulo. Apresenta duas modalidades de mecanismos de segurança que acionam circuitos de intercâmbio entre norma biológica e norma jurídica como forma de garantir a construção do indivíduo perigoso e a manutenção de dispositivos de exclusão e violência. Pontuando a lógica que os atravessa, em diálogo com o estado penal e a biopolítica, destacamos o sofrimento dos internos como um dos efeitos desta lógica, buscando fazer ecoar o intolerável e ativar lutas que impeçam a ampliação da rede penal. Apontamos, por fim, algumas pistas para uma ação ético-política neste âmbito, pontuando as condições de enunciação desse sofrimento em uma política da narratividade.

Palavras-chave: Política da narratividade; Sofrimento; Manicômio judiciário; Mecanismo de segurança. 


\begin{abstract}
The article discusses the suffering prisoners of a judiciary asylum, and a simulacrum of that, respectively: Hospital de Custódia e Tratamento Psiquiátrico in Pará and Unidade Experimental de Saúde in São Paulo. Presents two types of security mechanisms that drive circuits of exchange between biological norm and juridic norm in order to ensure the construction of dangerous individual and maintenance of devices of exclusion and violence. Punctuating the logic that crosses in dialogue with the state criminal and biopolitics, we highlight the suffering of the inmates as one of the effects of this logic, searching echoing the intolerable and activate struggles that prevent the expansion of the criminal network. Pointed out, finally, some clues for an ethical-political action in this area, pointing out the conditions of enunciation that suffering in a policy narrative.
\end{abstract}

Keywords: Politics of narrativity; Suffering; Asylum judiciary; security mechanism.

\title{
Resumen
}

El artículo aborda la difícil situación de los presos que viven en judicial manicomio y una semblanza de esta, respectivamente: Hospital de Custódia e Tratamento Psiquiátrico in Pará and Unidade Experimental de Saúde in São Paulo. Presenta dos tipos de mecanismos de seguridad que disparan circuitos de intercambio entre norma biológica y el norma juridica, a fin de garantizar la construcción de los individuos peligrosos y el mantenimiento de los dispositivos de la exclusión y de la violencia. Puntuando la lógica que atraviesa un diálogo con el estado criminal y la biopolítica, se destaca el sufrimiento de los presos como uno de los efectos de esta lógica, buscando eco de lo intolerable y activar las luchas que impiden la expansión de la red criminal. Señaló, por último, algunas claves para una acción ético-política en la materia, señalando las condiciones de enunciación que sufren desde una política de la narratividad.

Palabras clave: Política de la narratividad; el sufrimiento; judicatura Asylum; el mecanismo de seguridad.

Este artigo visa colocar em pauta o sofrimento de internos de instituições totais, recentemente erguidas na contramão do processo de Reforma Psiquiátrica vivida no Brasil há quase três décadas: Hospital de
Custódia e Tratamento Psiquiátrico do Pará e a Unidade Experimental de Saúde de São Paulo.

O Hospital de Custódia e Tratamento Psiquiátrico (HCTP), chamado até a Lei 
de Execução Penal (1984) de manicômio judiciário, é o lugar para onde são encaminhadas as pessoas com suspeita ou diagnóstico de algum transtorno mental e que cometeram algum delito. Teoricamente serviria às pessoas que, não conscientes do ato ilícito que cometeram ou incapazes de determinar-se de acordo com a ilicitude do fato, oferecem sérios riscos a si e à outrem e devem cumprir medida de segurança - considerado um tratamento psiquiátrico - até que cesse sua suposta periculosidade. Porém, longe de se configurarem como Hospital, estes espaços são de fato prisões.

Os HCTP's, no entanto, podem ser considerados ainda piores tendo em vista que as pessoas que aí entram, não têm prazo determinado para sair. Elas dependem de um exame de cessação de periculosidade que deveria ser feito anualmente, mas não o é e, sem acompanhamento em saúde mental e sempre olhadas pelo prisma da psiquiatria forense, a qual costuma ser bastante conservadora, quando passam por este exame não deixam de ser consideradas doentes e entendidas como perigosas. Daí o caráter, muitas vezes, perpétuo da medida de segurança.

A Unidade Experimental de Saúde no estado de São Paulo é, por sua vez, um simulacro de um Manicômio Judiciário. Estabelecimento único no Brasil, inaugurado em dezembro de 2006, foi criada por lei estadual, em um convênio entre as Secretarias da Saúde, Justiça e Administração Penitenciária, para oferecer tratamento para adolescentes autores de ato infracional portadores de diagnóstico de transtorno de personalidade e/ou de periculosidade, em regime de contenção, alargando, assim, o tempo de internação dos jovens (que poderá ser, inclusive, indefinido), por meio do acionamento da interdição civil. Juridicamente, trata-se de um arranjo que transforma a medida socioeducativa em protetiva para uma internação psiquiátrica compulsória, que,em seguida, é adicionada a uma interdição civil, num simulacro de medida de segurança.

Sua emergência delineia um vetor central da política de gestão da criminalidade juvenil de São Paulo: o da construção do jovem perigoso, “intratável”, portador de Transtorno de Personalidade Antissocial (TPAS) que justifica este continuum internamento (Gramkow, 2012). Acionando estratégias de exílio, inabilitação, imunização e aniquilamento, tal política se vale de engrenagens de exceção (Agamben, 2002), em nome da proteção social (Gramkow, 2012).

Após delinearmos brevemente $o$ contexto de produção desses aparatos e os dispositivos pelos quais atua, produzindo "anormais" e indivíduos "perigosos" para justificar táticas de guerra contra a própria população, apresentamos expressões do sofrimento das pessoas aí enclausuradas para 
daí extrairmos algumas pistas de trabalho em que a expressão e a narrativa do insuportável de suas vidas reclusas e negadas possam "interrogar os silêncios da história" (Meunier, 1999 , p. 84-85), configurando atos que alterem certos regimes de verdade.

\section{Mecanismos de segurança e racismo de}

\section{estado: manicômios judiciários e seus}

\section{simulacros}

A globalização da política de Tolerância Zero e o consequente encarceramento em massa, iniciados na década de 70 nos EUA e fortalecidos após o 11 de setembro, sinalizaram ao mundo a instauração de um Estado Penal (Wacquant, 2001), concomitantemente ao Estado Democrático de Direito, com práticas que influenciam fortemente os países da América Latina. Com efeito, no Brasil, nos anos 1990 e 2000, assistimos a um aumento vertiginoso da população carcerária. Segundo os dados do DEPEN (Departamento Penitenciário Nacional), em 1990, havia no sistema penitenciário 90 mil presos; em 2012, esse número chega a quase 550 mil, o que significa um aumento de $511 \%$ da população carcerária no país.

Para Wacquant, desenvolver o Estado penal é restabelecer uma verdadeira ‘ditadura sobre os pobres', já que o mesmo funciona para: responder às desordens suscitadas pela desregulamentação da economia, pela dessocialização do trabalho assalariado e pela pauperização relativa e absoluta de amplos contingentes do proletariado urbano, aumentando os meios, a amplitude e a intensidade da intervenção do aparelho policial e judiciário (Wacquant, 2001, p. 10).

Nesse sentido, não apenas autoriza-se o uso da violência estatal, como permite-se práticas extremas de arbitrariedade, sem que ninguém se escandalize, como era de se esperar, a exemplo de métodos de tortura como formas de investigação - desde que direcionadas aos setores da sociedade identificados como suspeitos ou perigosos. Como diz Tânia Kolker (2002, p. 93): “Quando pensávamos que as democracias modernas teriam mais instrumentos para coibir a violência estatal, verificamos que a tortura coexiste muito bem com a ordem constitucional".

Temos, assim, a transposição dos dispositivos do Sistema Internacional de Segurança, que deveriam servir para a garantia da soberania do país, para o Sistema de Segurança Nacional, em que as táticas de guerra passam a ser utilizadas contra a própria população com vistas a garantir a ordem. Um exemplo atual são as ações da polícia militar, única da América Latina que não foi desmilitarizada, diante das manifestações sociais iniciadas em junho de 2013 
e que se irradiaram por várias cidades do país: em resposta a manifestações pacíficas, prisões arbitrárias (por carregar vinagre!), confrontos com bombas de gás lacrimogênio, sprays de pimenta, balas de borracha e cacetes. Cenas de guerra que as camadas populares vivem cotidianamente, sendo que enfrentando balas de verdade; toques de recolher; invasões domiciliares, sem mandado de segurança; mortes registradas como Resistência Seguida de Morte (RSM); desaparecimentos, dentre outros absurdos.

O recrudescimento das políticas criminal e penitenciária, previsto como solução para a exclusão social, coloca a privação da liberdade como tática central para lidar com os indesejáveis, seja em prisões, hospitais psiquiátricos, manicômios judiciários para adultos ou jovens, centros de internação, dentre outros. Os processos de patologização e judicialização se fortalecem dentro de máquinas médico-jurídicas, legitimando o enclausuramento em nome da proteção e do direito à saúde.

É deste modo, em defesa da sociedade ou da democracia, que se criam novos e velhos inimigos, os quais devem ser eliminados segundo a lógica do racismo de estado, discutido por Foucault. Em seu curso "Em defesa da sociedade", ele explica como entender em termos de racismo de estado determinadas racionalidades e tecnologias que parecem ir na contramão de um poder que quer fazer viver, destruindo a vida, expondo determinada população a perigos ou situações que quando não matam, mortificam subjetividades, como no caso dos manicômios judiciários. O racismo exerceria uma dupla função: a de produzir uma separação, dentro do continuum biológico, entre quem pode viver e quem pode morrer, articulando as duas condições: a morte de uns favorece a sobrevivência dos outros (Foucault, 1999).

Jovens e adultos associados com a periculosidade (especialmente os do circuito infracional e o circuito "uso de drogas"), têm sido o alvo recorrente desta estratégia e estão cada vez mais regulados por circuitos de intercâmbio entre norma biológica e norma jurídica, no âmbito de uma lógica biopolítica (Foucault, 1999).

No contexto acima descrito, de uma sociedade punitiva (cf. Wacquant, 2001, 2008), e de produção de medo social (cf. Kolker, 2005), uma indiferença face à situação de sofrimento vivida tanto por adultos quanto por adolescentes privados de liberdade tem sido uma constante (Arantes, 2009), como vemos, com a Unidade Experimental de Saúde (UES), em São Paulo, e com o Hospital de Custódia e Tratamento Psiquiátrico de Santa Izabel do Pará.

Se tomamos o tema do sofrimento como perspectiva de trabalho neste texto, não é para reduzir as desigualdades ou 
a violência ao sofrimento, conforme alerta Fassin (2010). O autor sinaliza um risco presente nas atuais políticas de ajuda a imigrantes, refugiados e populações em situação de vulnerabilização (especialmente a juventude das periferias na França): o de que as "desigualdades sejam traduzidas como sofrimento social, as violências em termos de traumatismos e as questões políticas em termos humanitários" (Fassin, 2010, p. 38, tradução nossa). Muito menos tomamos o sofrimento aqui apenas como um dado ou a conseqüência de um fato, este sim a ser analisado. Ao contrário, na esteira de Farge (2011) e Ferrandiz (2002, 2005), entendemos a dor como um modo de ser no mundo que varia segundo os tempos e as circunstâncias; que pode se exprimir ou, ao contrário, se recalcar; que se insere em processos que podem ser explicados e combatidos, podendo ou não se transformar em ação política.

Há racionalidades do abominável. (...) Uma sociedade que se debruça sobre os mecanismos de racionalidade que organizam seus modos de produção de violência e de sofrimento é uma sociedade que faz 'existirem' aqueles que a dor aniquila e que pode, se o desejar, encontrar outras formas de racionalidade para pensar de outro modo a 'noite da violência que faz o homem se erguer contra o próprio homem' (Boyer, 'La vie fraternalle", Furor, n. 27). (Farge, 2011, p. 23).

\section{Falar o sofrimento: vozes de internos do HCTP do Pará e a UES de São Paulo}

O Hospital de Custódia e Tratamento Psiquiátrico no Estado do Pará, inaugurado no ano de 2007, foi o último a ser posto em funcionamento no Brasil. Construído através de convênio entre Departamento Penitenciário Nacional (DEPEN) e o Estado do Pará, com um custo previsto, em 2001, de 5,5 bilhões reais, localiza-se no município de Santa Izabel, a 60 km de Belém. Em suas 120 vagas, hoje tem, em suas celas, 227 internos e presos, número que vêm crescendo exponencialmente devido à transferência constante de presos provisórios, caracterizados, em sua grande maioria, como jovens, pobres e usuários de drogas. Na verdade, esse tem sido o novo perfil de boa parte da população institucionalizada no manicômio judiciário do Pará. Para exemplificar o que tem ocorrido no Estado, somente no mês de julho deste ano, de um único município do interior, chegaram seis jovens, entre 20 e 27 anos, com perfil semelhante: dois com laudo psiquiátrico atestando "Transtorno de Personalidade Anti-Social", e os demais com a suspeita do juiz de terem o mesmo transtorno. Coincidentemente todos os seis eram usuários de drogas em suas casas penais de origem.

Do total institucionalizado, 85 são pessoas que cumprem medida de segurança, 
o restante aguarda perícia como condenado ou sentença como preso provisório, todos geralmente transferidos de outra casa penal. Para admitir o preso nas dependências do HCTP, é procedimento que ele passe por avaliação psiquiátrica em clínica particular, localizada em município vizinho, já que não há médico psiquiatra em seu quadro funcional. O acompanhamento é dado pela equipe de enfermagem do HCTP que separa os psicotrópicos prescritos nos três turnos do dia para $85 \%$ da população internada, quando estes não faltam.

Corredores escuros e celas superlotadas, insalubres e com mau cheiro, amontoam pessoas em medida de segurança juntamente com presos provisórios e condenados, sem qualquer transtorno mental. Embora o setor de segurança aponte essa mistura como prejudicial às pessoas com transtorno mental, que acabam sofrendo violência por parte dos demais, o setor pensa-a como estratégia para desarticular possíveis mobilizações e motins, já que os presos provisórios transferidos de outras casas penais, mais recentemente, não conseguem manipular as pessoas em medida de segurança, impregnadas de medicamento.

Ao contrário dos dispositivos disciplinares que buscam "transformar as multidões confusas, inúteis ou perigosas em multiplicidades organizadas" (Foucault, 1987, p. 135), о НCTP parece funcionar Rev. Polis e Psique, 2013; 3(3):125-142 mais aos moldes dos mecanismos de segurança ou de regulação, tais como teorizados por M. Foucault (2008). Nesta lógica de poder, uma margem ótima de irregularidade é permitida para fazer melhor funcionar uma série de outros sistemas, sempre baseados em cálculos que apontam vantagens e desvantagens com relação às práticas de repressão e com balanços que descrevem seus prejuízos para os Estados em termos de custos (Foucault, 2008). Nesse sentido, não interessa a condição de violência em que se encontram os indivíduos aí enclausurados, mas interessa prezar pela segurança entendida nesses termos.

Como estratégia de visibilidade da situação em que vivem as pessoas que cumprem medida de segurança no Hospital de Custódia e Tratamento Psiquiátrico de Santa Izabel do Pará, realizamos ${ }^{1}$ oficinas de fotografia e gravura junto a 18 internos da instituição, ministradas por artistas visuais, objetivando apresentar seus trabalhos em exposições itinerantes por vários espaços da cidade de Belém.

Durante as duas semanas de realização das oficinas, fomos os escutadores das angústias diárias de alguns internos participantes, através de sussurros, quando das breves ausências dos agentes penitenciários que nos vigiavam em sala. Os "homens de preto", geralmente transferidos de outras casas penais, portanto, com larga cultura 
carcerária, nos alertavam sempre que podiam, dizendo para termos cuidado diante do "perigo" que os internos ofereciam. Justificavam, assim, sua presença intermitente na sala e nos deixavam sempre de sobreaviso, vigilantes sobre nossas conversas que a todo momento se interrompiam ou nem mesmo eram anunciadas, no caso dos mais temerosos em receber repreensões.

As imagens produzidas a partir da técnica da xilogravura (gravura em madeira), escolhidas para este artigo, relatam histórias semelhantes: um idoso, de 71 anos, e um jovem, de 27 anos, expressam a injustiça de estarem cumprindo medida de segurança sem laudo psiquiátrico. A internação compulsória para ocorrer requer, além da guia de internação expedida pelo juiz, um "laudo médico circunstanciado que caracterize os seus motivos", conforme o artigo $6^{\circ}$ da Lei 10.216/2001. As imagens abaixo são respectivamente de José e Paulo²:

Figuras 1 e 2

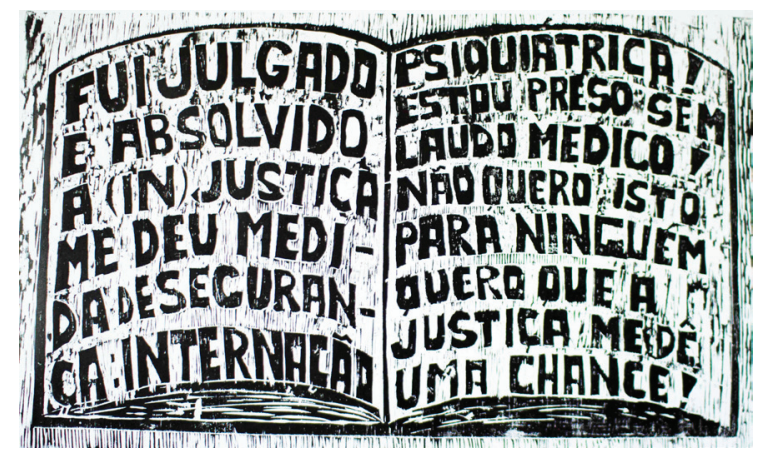

Figura 1

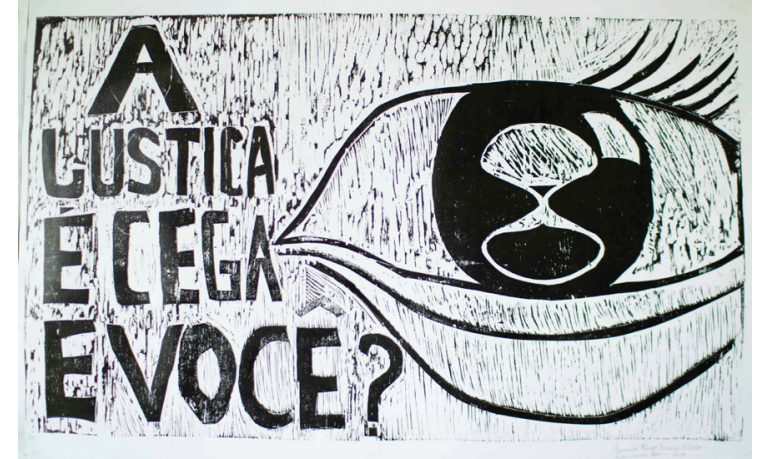

Figura 2

José, sempre preocupado com quem passa pela porta, conta baixo parte da sua história no livro que, devido a seu analfabetismo, produziu com a ajuda dos demais participantes da oficina:

Pra te falar a verdade não sei nem assinar meu nome, mas já que trouxeram essa ideia eu resolvi historiar isso aqui, contar um pouco da minha história. Aqui também não tem como contar de outro jeito, né? Aqui a gente não pode falar muitas coisas... O negócio aqui não é fácil não. (...) quando a gente tá de trás da cela, a gente pensa muita coisa que rola que a gente não imaginava. Sofre angústia, sofre desagrado. A família mora longe e não vem visitar. Passa tempo e a gente acha que tá esquecido.

Por uma situação de briga de bar, José, foi acusado de tentativa de homicídio. Passou dois anos na cadeia comum e, por estar na ocasião do ato alcoolizado, foi transferido para o HCTP sem laudo médico, como ele próprio relata. Sua cidade localizada a $300 \mathrm{~km}$ de Belém inviabiliza sua 
família de vir visitá-lo. Por ser réu primário e idoso, poderia estar respondendo em liberdade.

Ao mesmo tempo, Paulo comenta a injustiça que vive:

Já passei por quatro psiquiatras e nenhum atestou nada. Você acha que é não é injustiça a justiça te mandar pra um lugar que você não merecia tá lá? Eu não tô falando que eu não merecia tá preso; mereço, eu cometi um erro. Mas (...) não queria tá num hospital onde ficam pessoas com problemas mentais, com algum tipo de distúrbio ou esquizofrenia. (...) Eu tô aqui há dois anos e um mês, nunca briguei, nunca fui pra MD [medida disciplinar], ou seja, quando briga ou discute, fica isolado, vai puxar um castigo de dez a quinze dias (...). Isso aqui, pra mim, praticamente acabou com a minha vida. Eu não sabia que o juiz que estuda direito, estuda também algum tipo de psicologia, porque ele me deu medida de segurança sem laudo psiquiátrico, sem laudo médico, por conta própria.

\section{A Lei de Execução Penal} (7.210/1984), diante de uma falta disciplinar do preso, prevê o isolamento em local adequado como sanção disciplinar (Art. 53, Inc. VI). No HCTP, o castigo aos insubordinados é a medida disciplinar (MD), ou seja, isolamento do interno em uma cela que mais se assemelha ao uma jaula de $1 \mathrm{~m}^{2}$, onde os castigados ficam por pelo menos dez dias, o que pode se estender, dependendo do caso. Segundo outro interno: "A pessoa vira um bicho lá. Além de urinar e defecar no chão, dorme num pedaço de espuma num calor infernal e acorda todo mordido de carapanã [pernilongo]".

Raimundo, 28 anos, participante da oficina de fotografia, questiona o HCTP falando que "em um Hospital não se usa pernamanca para 'arriar' interno. (...) e quando a gente se queixa de dor, pra conseguir um medicamento tem que fazer muito barulho pra ser levado pra enfermaria, isso quando eles não dizem que não tem medicamento". A enfermaria, primeira foto abaixo, foi o limite determinado pela direção para realizar as fotos com câmeras artesanais (denominadas Pinhole e Pinlux): não era possível fotografar "lá em baixo", como é chamado por internos e funcionários o espaço onde se encontram as alas carcerárias. "Em cima" localizam-se o setor técnico e administrativo do HCTP. O portão na foto ao lado da enfermaria separa a parte de "baixo" da parte de "cima" do HCTP. De qualquer maneira, as fotos prenunciam o que pode ser encontrado depois dele:

Figuras 3 e 4

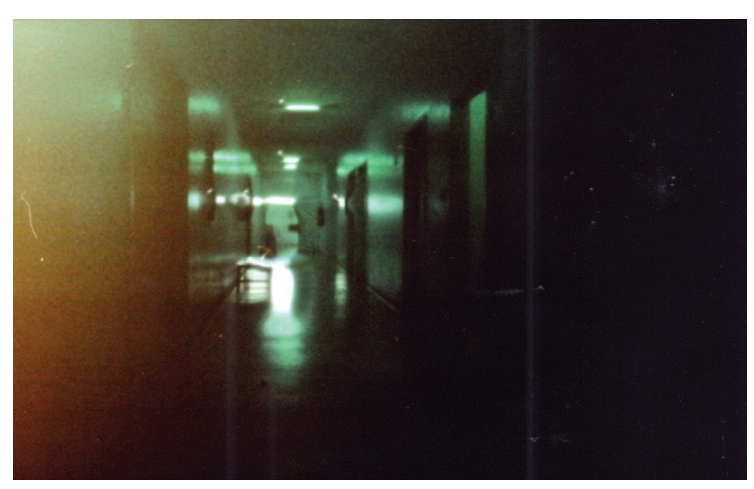

Figura 3 


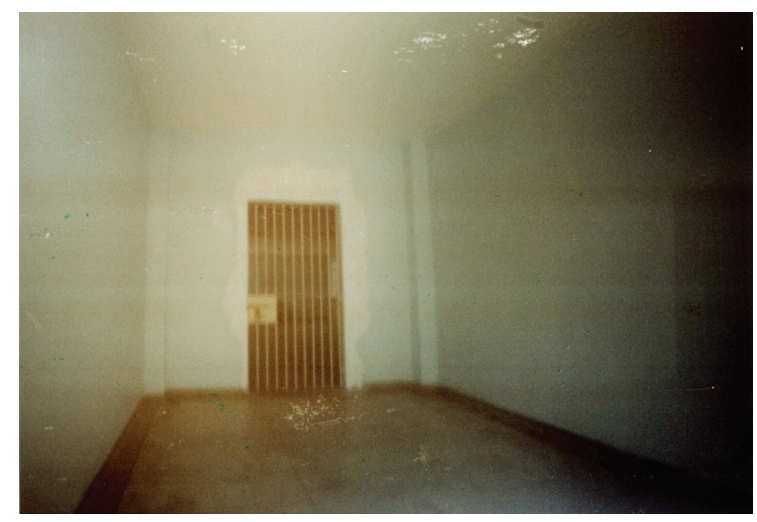

Figura 4

Sobre a atuação da psiquiatria forense do Estado, é interessante trazer a fala de um outro interno que participou da oficina de fotografia. Em um dos intervalos da oficina, ele traz sua apreensão quanto ao exame de cessação de periculosidade e a possibilidade da duração perpétua da medida de segurança:

Não consigo compreender os critérios que a psiquiatra do IML usa para avaliar os internos. Eles precisam entender que cada pessoa tem seu modo de se expressar, sua cultura, suas gírias. Eu falo de um jeito e ele fala de outro. Cada um fala de um jeito diferente. Ela [psiquiatra forense do IML] tinha que entender essas diferenças a partir de cada um. Mas parece que todos tem que falar somente de um jeito dentro daquilo que ela entende ser normal. (...) Tem também o fato de que a pessoa espera tanto tempo para passar por esse exame que na hora fica nervosa e não passa. (...) Se eu que me expresso bem e sei que me faço entender não passei, como algumas pessoas que não conseguem nem falar direito vão um dia passar. Fiz uma perícia no ano passado e não passei. Fiz uma reavaliação em maio desse ano, mas ainda não saiu o laudo. Se eu não passar de novo, nem sei o que vai ser de mim, acho que vou desistir.

Antonio, 51 anos, está preso há quase 10 anos, sendo que há seis anos cumpre medida de segurança. Cometeu homicídio e, como tinha o hábito de beber, recebeu o diagnóstico de Síndrome de Dependência de Álcool. É réu primário e, por isso, já poderia estar de livramento condicional, já que cumpriu muito mais que um sexto do tempo previsto para a pena máxima referente ao crime cometido. No entanto, está a mercê da avaliação de um dos três psiquiatras forenses do Estado.

Em outubro de 2013, no III Encontro de Execução Penal do Tribunal de Justiça do Pará, o qual abordou exclusivamente o tema da medida de segurança no Estado, foi apresentada uma Exposição, intitulada "Restos Manicomiais", com várias das imagens produzidas nas oficinas. Dez internos do HCTP, que estiveram presentes no evento, puderam falar por si e pelos demais sobre seus sofrimentos e foram escutados, para além do circuito médico-jurídico, por mais de 200 pessoas. Estas narrativas, que melhor abordaremos mais à frente, se conseguirem escapar ao caráter de denúncia do sofrimento e de apelos humanitários, para ensejarem a análise de certas racionalidades 
e tecnologias do "continuum internamento", podem ganhar um estatuto político.

Passemos agora às narrativas dos jovens internos da Unidade Experimental de Saúde de São Paulo. A UES mantém internados atualmente (e desde 2007-2008) cinco jovens, pelo menos há 6 anos (o sexto foi desinternado neste ano de 2013). Se contarmos os 3 anos relativos ao período de cumprimento de medida socioeducativa na Fundação Casa, serão 9 anos de privação de liberdade e sem previsão de saída (Gramkow, 2012).

Em 14/05/2012, como parte das estratégias de enfrentamento da UES, desenvolvida pelo Grupo Interinstitucional Saúde Mental e Justiça (grupo que reúne ativistas dos sistemas de justiça, da rede de saúde e de instituições formadoras) construiu-se um seminário $^{3}$ em que foi possível presentificar os jovens lá internos, presos políticos do nosso Tempo, por meio de cartas. Foi a primeira vez que tais vozes em sua dimensão de sofrimento puderam ter lugar num evento público. Lidas ao lado das falas dos participantes, juízes, psiquiatras, representantes das políticas de saúde para adolescentes em cumprimento de medida de internação, as cartas produziram um efeito desconcertante relativamente ao discurso da proteção e do suposto tratamento. Um dos jovens descrevendo o cotidiano prisional interroga: "onde está tratamento? E pede para não "servir de instrumento para estudo da transformação das políticas de saúde”.

Vejamos outra destas vozes:

É por meio desta [carta] que venho até vocês hoje. Creio que devo me apresentar. Meu nome é Bruno. Tenho 23 anos e sou interno exilado na Unidade Experimental de Saúde, aonde me encontro atualmente detido contra a minha vontade por motivos e razões que sinceramente não entendo. Fui enviado a esta localidade por autoridades do poder público e judiciário, embargado nas promessas que aqui iria encontrar um tratamento adequado de ressocialização com uma assistência apropriada e necessária a minha situação. Mas a realidade a qual me deparei não foi a prometida pelos mesmos, e, sim o inverso, pois me deparei com uma unidade vazia no composto geral, mal fundamentado e aos olhos de muitos ilegal perante a lei. Já estou aqui há quatro anos sem uma assistência adequada, após três anos cumprindo medida socioeducativa na extinta FEBEM e agora Fundação CASA, que na minha humilde opinião, nada mais foi que um sistema carcerário semi-juvenil, maquiado por trás das leis do ECA, aonde fui mandado para ser punido e ressocializado aos olhos da lei e da sociedade, mas posso afirmar com propriedade, pois vivi a realidade de uma Fundação que nada mais foi na minha época uma escola do crime, muito eficaz por sinal, aonde aprendi muitas coisas erradas. E foi nessa mesma situação que comecei a perceber que estava sendo iludido, e logo vi a ilusão composta de maldade, sangue, raiva e tristeza maquiado pelo poder e dinheiro do crime. Já na intenção de mudança e 
de auto regeneração no fim da internação da Fundação CASA, fui abordado por pessoas do poder público e judiciário que me convenceram por meios técnicos que o melhor para mim era esta unidade. Mas aqui estou completamente abandonado, vegetativo socialmente [...] (Carta de Bruno, 14/05/12).

Mas a expressão de sofrimento se agudiza no caso de Marcos, desinternado finalmente, depois de uma tentativa de suicídio que se dá no interior da UES. A desinternação se ancora nos questionamentos feitos pela Defensoria e pelo Ministério Público com base em pareceres de profissionais da saúde que sustentam que a internação não possui qualquer papel terapêutico do ponto de vista médico-psicológico. (Gramkow, 2012). Evidencia-se, assim, a iatrogenia institucional, na medida em que a declaração de um campo de saber, o da saúde, atesta a inoperância da internação e o sofrimento ganha força política pelo suicídio e consequente desinternação.

Mas é a situação-problema de Leandro que nos mostra como a UES participa da construção da trajetória do jovem periculoso: ele ingressará no sistema penal por cometimento de ato infracional: um incêndio realizado no seu próprio colchão, quando internado na UES. Trata-se de jovem com trajetória institucional longa (2004-2009), mas de breves passagens, todas por atos inRev. Polis e Psique, 2013; 3(3):125-142 fracionais leves: a maioria furto ou roubo, com medidas socioeducativas que foram da internação à semi-liberdade e LA, esta última associada com medida protetiva de tratamento num CAPS. Mesmo assim, foi encaminhado para a UES, cujo perfil, recordemos, é para ato infracional grave, em função do diagnóstico de epilepsia e transtorno anti-social, apontado em exames realizados pela Equipe Técnica do Juízo. Durante seu processo de internação, Leandro realiza nove auto-lesões com lâmpadas, as quais tiveram como principal encaminhamento, além de sua contenção corporal, a produção de vários boletins de ocorrência. As referências às auto-lesões nas avaliações técnicas, nos informes ao órgão corregedor e, inclusive nas audiências de seu processo, corroboravam sua conduta anti-social: "É seu comportamento habitual provocar ferimentos para chamar atenção, vingar-se ou tentar sair da unidade" (relatório médico da UES, 13/05/08). Pouco tempo depois, o caso é reavaliado pela mesma Equipe Técnica do Juízo que testemunha "uma rotina de absoluta ociosidade" e "tratamento que se resume à hiper-medicalização" (Relatório, 26/05/08), solicitando seu retorno ao sistema socioeducativo.

Em seu período de internação na UES, uma das avaliações de um psiquiatra na função de perito, transforma o discurso, talvez até anedótico, do jovem em subsídio 
de seu "alto nível de sua "periculosidade": "realizou vários homicídios subseqüentes!", ainda que de acordo com o registrado nos processos judiciais, seus atos infracionais envolvessem majoritariamente abordagens sem uso de armas para furto e/ou roubo de celular, e fossem frustradas em flagrante por policiais. Passa-se assim, nas malhas do próprio percurso institucional, de furto/roubo e auto-lesões à conduta de alta periculosidade e de história infracional grave, mesmo sem provas judiciais! (Gramkow, 2012).

Finalmente, para que não tenhamos dúvida de que a divisão entre os que devem morrer e os que não devem morrer se faz presente no funcionamento da UES, vejamos a fala de um dos promotores de um dos casos lá internados, também extraído da pesquisa de Gramkow (2012):

A propósito disso [da gravidade do ato infracional], este subscritor está absolutamente convencido que a correta medida a ser aplicada deveria de ser a morte do adolescente, se possível fosse, mesmo sendo menor irresponsável o autor dos estupros. Ocorre, todavia, que o Brasil ainda não se desenvolveu suficiente para aceitar a inexorável conclusão segundo a qual, para sancionar casos que tais, apenas pena de morte seria adequada (Promotor de Justiça, no Processo socioeducativo, caso Lucas, 21/06/04, grifos nossos).
Na gestão dos corpos na UES e no HCTP, podemos dizer que encontramos um híbrido de distintas produções de sofrimento: a) uma espécie de mil mortes (Foucault, 1987), pelos dias que não contam seu fim, na perspectiva de uma prisão perpétua. $\mathrm{Ou}$ na forma da "A vida como castigo", como sugere Cesaroni (2010), referindo-se aos jovens em prisão perpétua na Argentina $\left.{ }^{4}\right)$; b) a produção de uma experiência de mortificação (Goffman, 1974) que se expressa de diversas formas: exaustão, medo e desamparo, sentida tanto pelos internos, quanto pelos profissionais que deles se ocupam em função da segregação aliada às condições de empobrecimento da vida descritas por Bruno, pelos internos do HCTP e visível na tentativa de suicídio de Marcos.

Mas outro tipo de produção de sofrimento pôde ser vista com o caso de Leandro e dos internos do HCTP: é por meio do distanciamento social e principalmente pela hipertrofia dos aparatos de segurança que se multiplicam as situações ameaçadoras, se incrementam as estratégias puramente defensivas, se reduz a tolerância social frente aos conflitos e se ampliam as situações de encarceramento. Neste caso, a periculosidade é produto dos códigos interpretativos e das tecnologias de intervenção das próprias instituições que reproduzem a norma e exercem o controle. 


\section{Por uma política da narratividade}

Nos dois casos acima apresentados, a expressão e a narrativa compõem parte de uma luta. "A informação é ela mesma uma luta" (Artieres, 2004, p. 144), ao modo do que foi o Grupo de Informações sobre as Prisões (GIP), que na França, no início da década de 1970, com suas enquetes nas prisões, construiu uma potente narratividade das "vidas presas"

Nesta intervenção, da qual participou Michel Foucault, buscou-se formar um coletivo em que pudessem tomar a palavra os próprios detentos, assim como vários intelectuais (técnicos, juristas, jornalistas) que já não toleravam mais sua cumplicidade no exercício da opressão e do poder político. O grupo, defendendo a circulação de informações, realizou uma pesquisa com detentos sobre as condições do sistema carcerário, inspirado nos instrumentos que o proletariado havia criado no século XIX: as pesquisas feitas pelos próprios operários sobre a condição operária. Seu objetivo não é acumular conhecimentos, nem mesmo fazer com que as pessoas tomem consciência, mas "difundir o mais amplamente as revelações feitas pelos próprios prisioneiros" (Eribon, 1990, p. 211).

Nas palavras de Foucault, "gente que havia sido, por gerações e gerações, excluída não somente do poder político, mas do direito a falar, descobre (...) que o poder estava de alguma forma ligado aos direto à palavra" (Radio Canadá, 1971, citado por Artieres, 2004, p. 149).

De fato, Foucault (1999) percebeu a enorme importância de (re)colocar os saberes desclassificados, sujeitados ou desqualificados na cena política, pela sua potência de sublevação, de insurreição. Para ele, nesses saberes jaz a memória dos combates - que tinha sido mantida sob tutela, e a potência de dispor dos próprios problemas e de fazer a crítica.

Como nos diz Portelli (2010, p. 02), trata-se de que "essas vozes - que, sim, existem, porém ninguém as escuta, ou poucos as escutam - tenham acesso à esfera pública, ao discurso público, e o modifiquem radicalmente".

Criar as condições para a expressão/ enunciação do sofrimento e dos modos de vida que aí se produzem é uma via de trabalho que nos parece central em contextos de violência de estado. Ou seja, as situações de dor, humilhação, sofrimento e violação de direitos poderiam desaparecer, como costuma acontecer, nos segredos e conluios dos agentes institucionais e em infindáveis processos de apuração que só confirmam a periculosidade dos internos, mas podem ganhar outro destino, alterando o regime de verdade, com as oficinas-exposição e a construção do seminário-carta. 
No caso das oficinas no HCTP do Pará, acionou-se as artes visuais como ferramentas conceituais e técnicas que podem funcionar como bombas-relógio capazes de implodir concepções, revirar modos de existir, quebrar práticas engessadas, bem como possibilitar espaços de vida menos arbitrários, quiçá mais libertários. Para limitar o sofrimento das pessoas internadas no HCTP, a arte por meio da qual falam suas dores pode atuar como dispositivo de saída do exílio. Pensamos ser possível desconstruir, por enquanto metaforicamente, os muros que nos separam deste mundo para tornar visível a realidade de violações e contradições vivenciadas pelas pessoas diagnosticadas com transtornos mentais em conflito com a lei, fazendo fissuras na articulação arbitrária existente entre a concepção de loucura e perigo.

Na UES é a narrativa-carta, não prevista pelos discursos distantes e técnicos dos gestores que produz um efeito de crítica em ato, numa inversão de poder, ainda que momentânea: a carta é negação das falas do psiquiatra, da direção da unidade que ficam, no mínimo, embaraçados.

Entendemos ser necessário ainda que a expressão/narrativa transmita a dimensão política que encarnam - isto é, um modo de agir no mundo; é necessário que trabalhem uma dimensão ética, transformando a experiência do horror em história, e, ainda, que trabalhem uma dimensão estética, constituindo uma espécie de dramaturgia do real.

No texto "A vida dos homens infames", Foucault (1992) registra o impacto que teve sobre ele a leitura de fragmentos de existências, encontradas a esmo em alguns documentos com os quais trabalhava. Estes fragmentos de "vidas ínfimas", "lendas de homens obscuros", Foucault chamou de "existência-clarão" ressaltando que "aquelas vidas, que estavam destinadas a passar ao lado de todo o discurso e a desaparecer sem nunca terem sido ditas, não puderam deixar traços - breves, incisivos, enigmáticos muitas vezes - senão em virtude do seu contato momentâneo com o poder (Foucault, 1992, p. 98-99).

Buscando sustentar este efeito-intensivo, Foucault construirá uma espécie de método de escrita/narratividade. Sua ideia central seria que estas narrativas mantivessem sempre relações com a realidade, isto é, não apenas que a ela se referissem, mas que nela operassem; que fossem uma peça da dramaturgia do real (Foucault, 1992, p. 95, grifos nossos), quando não se pode "manter face a elas a distância do olhar, da memória, da curiosidade ou do divertimento".

Daí, a necessidade de uma política da narratividade, "entendendo que o conhecimento que exprimimos acerca de nós mesmos e do mundo não é apenas um problema 
teórico, mas político" (Passos e Benevides, 2009, p. 151). Isto é, ao definirmos uma forma de expressão do que se passa, tomamos uma posição. No caso de pesquisas e de intervenções, não se separam, portanto, o ethos da pesquisa do ethos da clínica, aqui entendidos como lócus de escuta/expressão e de produção de sujeitos (cf. Passos e Benevides, 2009).

A expressão e as narrativas destas existências só podem fazer sentido se trabalham para limitar a "negação da vida", para "limitar o sofrimento" (fazemos alusão ao trabalho de N. Christie, Limits to Pain: The Role of Punishment in Penal Policy, disponível para download em www.jus.uio. no/ifk/forlag/limits-to-pain), se fazem ecoar o intolerável e ativam lutas para "impedir a multiplicação de medidas que ampliem a rede penal" (Wacquant, 2008, p. 104).

No caso do Brasil, a persistente violência de estado nas prisões, HCTPs e internatos coloca para profissionais, pesquisadores e ativistas, compromissos com a produção da informação relativa às vidas presas, principalmente quando "casas de custódia e prisões tornaram-se organizações opacas em que pode ser muito difícil e às vezes impossível penetrar" (Wacquant, 2004, p. 25). A narratividade pode realizar a nosso ver um combate à violência de estado sempre que puder evidenciar e argüir as racionalidades vigentes.

\section{Notas}

${ }^{1}$ Pesquisa de doutorado da autora deste artigo sob orientação da coautora, em andamento, no Programa de Estudos Pós Graduados de Psicologia Social, da Pontifícia Universidade Católica de São Paulo (PUC-SP).

2 Em cumprimento à Resolução 196/96, aos participantes da pesquisa foi garantida a sua confidencialidade, portanto, os atores envolvidos no estudo serão apresentados de modo genérico (com referência a sua vinculação institucional) ou quando referidos, faremos por meio de nomes fíctícios inventados pelas pesquisadoras.

3 O seminário "Balanço das políticas de saúde mental e juventude nas fronteiras psijurídicas", realizado na PUC-SP, visou: 1. avaliar a política de saúde mental do sistema socioeducativo privativo de liberdade refletindo os desafios e perspectivas e 2 . analisar o caso UES como estratégia de medida de segurança juvenil. Participaram do seminário diversos gestores das políticas de saúde e de justiça juvenil. Neste encontro os jovens participaram do evento indiretamente por meio da apresentação de cartas lidas ao longo do evento na presença de seus familiares.

${ }^{4}$ Nesse país latino-americano, foi imposta a prisão perpétua a seis adolescentes com condenações no período de 1999 a 2002. 
Essa história persiste atualmente (cinco jovens continuam presos e um cometeu suicídio) ainda sem soluções. Instâncias nacionais e internacionais condenaram a prática: o UNICEF em 2005 considerou-a uma violação dos Direitos das Crianças; a Corte Suprema da Justiça da Nação Argentina em 2005 julgou a estratégia como inaplicável; o Ministro da Justiça da Argentina em 2006 analisou a política como inconstitucional; e a Corte Interamericana de Direitos Humanos em 2008 denunciou a tática (Cesaroni, 2010).

\section{Referências}

Arantes, E. M. M. (2009). Pensando a Proteção Integral. Contribuições ao debate sobre a proposta de inquiração judicial de crianças e adolescentes. Em: Falando sério sobre a escuta de crianças e adolescentes envolvidos em situação de violência e a rede de proteção. Brasília: Conselho Federal de Psicologia.

Artieres, P. (2004). La sombra de los prisioneros sobre el tejado. Em: D. Eribon (Org.). El infrecuentable Michel Foucault. Renovación del pensamiento crítico. Buenos Aires: Eudeba e Letra Viva.
Cesaroni, C. (2010). La vida como castigo. Los casos de adolescentes condenados a prisión perpetua en la Argentina. Buenos Aires: Grupo Editorial Norma.

Eribon, D. (1990). Michel Foucault. Uma biografia. São Paulo: Companhia das Letras.

Farge, A. (2011). Lugares para a história. Belo Horizonte: Autentica Editora.

Fassin, D (2010). La raison humanitaire. Une histoire morale du temps present. Paris: Gallimard e Seul.

Ferrándiz, F. (2002). Malandros: Espacios de trauma, estigma y peligro entre jóvenes venezolanos. Em C. Feixa e cols. (Orgs.). Movimientos juveniles en America Latina. Pachuchos, malandros, punketas (pp. 65-78). Barcelona: Ariel Social.

Ferrándiz, F. (2005). Venas abiertas: Africanos y vikingos entre los jóvenes espiritistas venezolanos. Em: $\mathrm{F}$. Ferrándiz \& C. Feixa (Orgs.). Jóvenes sin trégua. Culturas y politicas de la violencia (pp. 171-184). Barcelona: Antrophos Editorail.

Foucault, M. (1987). Vigiar e punir: história da violência nas prisões. Petrópolis/ RJ: Vozes.

Foucault, M. (1992). A vida dos homens infames. Em: M. Foucault. O que é 
um autor?(pp.89-128). Lisboa: Veja, Passagens.

Foucault, M.(1999). Em defesa da sociedade. Curso no Collège de France (19751976). São Paulo: Martins Fontes.

Foucault, M. (2008). Segurança, Território, População. Curso no Collège de France (1977-1978). São Paulo: Martins Fontes.

Goffman, E. (1974). Manicômios, prisões e conventos. São Paulo: Perspectiva.

Gramkow, G. (2012). Fronteiras psijurídicas na gestão da criminalidade juvenil: $\quad$ o caso da Unidade Experimental de Saúde. Tese de doutorado. Curso de Pós-Graduação em Psicologia Social, Pontifícia Universidade Católica de São Paulo, SP.

Kolker, T. (2002). Tortura nas prisões e produção de subjetividade. In Clínica e política: subjetividade e violação dos direitos humanos. Equipe Clínico-Grupal, Grupo Tortura Nunca Mais - RJ. Rio de Janeiro: Instituto Franco Basaglia, TeCora.

Kolker, T. (2005). Instituições totais no século XXI. Em: M. Menegat \& R. Néri (Orgs.). Criminologia e
Subjetividade (pp. 109-121). Rio de Janeiro: Lúmen Júris Editora.

Meunier, J. (1999). Itinerário de uma criança normanda. Em: A. Novaes (Org.) A outra margem do Ocidente (pp.83-91). São Paulo: MincFunarte/Companhia das Letras.

Passos, E \& Benevides, R. (2009). Por uma politica da narratividade. Em: E. Passos; V. Kastrup \& L. Escócia (Orgs.). Pistas do método da cartografia. Pesquisa-intervenção e produção de subjetividade. Porto Alegre: Sulina.

Portelli, A. (2010). História Oral e Poder. Mnemosine, 6 (2), 2-13.

Wacquant, L. (2001). As prisões da miséria. Rio de Janeiro: Jorge Zahar.

Wacquant, L. (2004). O curioso eclipse da etnografia prisional na era do encarceramento de massa. Discursos Sediosos. Crime, Direito e Sociedade. Ano 8, número 13, 1 e 2 semestre de 2003. Rio de Janeiro, Instituto Carioca de Criminologia. Wacquant, L. (2008). As duas faces do gheto. São Paulo: Boitempo.

Recebido em: 31/08/2013 - Aceito em: 15/10/2013 